\title{
Type IV competence pili \\ in Streptococcus pneumoniae are highly dynamic structures that retract to promote DNA uptake
}

\author{
Trinh Lam ${ }^{1}$, Courtney K. Ellison ${ }^{2,3}$, Ankur B. Dalia ${ }^{4}$, David T. Eddington", \\ and Donald A. Morrison ${ }^{5}$. \\ ${ }^{1}$ Departments of Bioengineering and ${ }^{5}$ Biological Sciences, University of \\ Illinois at Chicago, Chicago, IL, USA \\ ${ }^{2}$ Lewis-Sigler Institute for Integrative Genomics and ${ }^{3}$ Department of \\ Molecular Biology, Princeton University, Princeton, NJ, USA \\ ${ }^{4}$ Department of Biology, Indiana University, Bloomington, IN, USA
}

Short summary. Competent pneumococci kill non-competent cells on contact. Retractable DNA-binding fibers in the class of type IV pili may provide a key tool for retrieving DNA segments from cell wreckage for internalization and recombination.

Funding statement. This work was supported by the National Institutes of Health [award R21Al133304 to DTE and award R35GM128674 to ABD] and National Science Foundation [NSF fellowship 1342962 awarded to CKE]

Conflict of interest. There are no conflicts to declare.

Contributions of Authors. AD, DM, and CE conceived and designed the study. TL performed the experiments. TL, DM, and $A D$ analyzed the data. $C E$ and $A D$ contributed reagents/materials/analysis tools. DM and TL wrote the paper. $A D$ and $D E$ edited the paper.

Correspondence. D. A. Morrison, Biological Sciences Department, UIC: 900 South Ashland Ave., Chicago, IL 60607. Tel: 1-312-718-5925. DAMorris@uic.edu 
SUMMARY The competence pili of transformable Gram-positive species form a subset of the diverse and widespread class of extracellular filamentous organelles known as type IV pili (T4P). In Gram-negative bacteria, T4P act through dynamic cycles of extension and retraction to carry out diverse activities including attachment, motility, protein secretion, and DNA uptake. It remains unclear whether T4P in Gram-positive species exhibit this same dynamic activity, and their mechanism of action for DNA uptake remains unclear. They are hypothesized to either (1) passively form transient cavities in the cell wall to facilitate DNA passage, (2) act as static adhesins to enrich DNA near the cell surface for subsequent uptake by membrane-embedded transporters, or (3) play an active role in translocating bound DNA via their dynamic activity. Here, using a recently described pilus labeling approach, we demonstrate that pneumococcal competence pili are highly dynamic structures that rapidly extend and retract from the cell surface. By labeling ComGC with bulky adducts, we further demonstrate that pilus retraction is essential for natural transformation. Together, our results indicate that Gram-positive type IV competence pili are dynamic and retractile structures that play an active role in DNA uptake.

Keywords: Streptococcus pneumoniae, Bacterial Pilus, Horizontal Gene Transfer. 


\section{INTRODUCTION}

Bacteria interact with their environment through various active physical mechanisms. Motility driven by rotating flagella that move the cell body through suspending liquids, for example, allows long-range exploration of liquid milieux, especially when coupled with temporal sensing of solutes of potential value or danger. At closer range, long thin protein appendages of a widespread class known as type IV pili support a different mechanism of directional motility, which operates much like the nautical grapnel or kedge anchor devices, by means of fibers that are alternately extended and retracted $[4,7,8,48,51,56,68,71,76]$. The retractile movement is actuated by one of the strongest biological motors known [46]. Type IV pili also support an array of biological functions not directly related to motility, including surface sensing [24], control of colony shape $[5,34,65,74]$, adhesion to surfaces or host cells $[13,28,33,59]$, and biofilm formation $[37,40]$, but these functions still depend on the retractile property of the fibers.

A fascinating variant on these type IV pilus-mediated functions is uptake of DNA by competent cells during natural genetic transformation, where the object moved is a DNA molecule, not a cell [1, 29, 32, 41, 64, 69]. In Gram-negative bacteria, some type IV pili, assembled either as microns-long extensions or as short 'pseudopili', are absolutely required for such DNA uptake $[1,2,11,29,32,41,49,66,69,72]$. Among these, the type IV competence pilus of Vibrio cholerae mediates DNA uptake by protruding perpendicularly to the cell surface, binding to DNA via its tip, and retracting to translocate bound DNA across the outer membrane into the periplasmic space [25].

Type IV pili are widespread within the Gram-positive bacteria [35], where they have roles in motility and adhesion much like those seen in the Gram-negative groups [63]. Evidence also

44 implicates a type IV pilus-like structure known as the com pilus in horizontal gene transfer in many 45 firmicutes species, where conserved ComG/PilD competence pilus operons are required for DNA 
uptake, but their mechanism of action remains obscure. The comG/pilD operons are most

47 thoroughly characterized in Bacillus subtilis, where they encode a short (pseudo)pilus, whose essential role in DNA uptake is thought to depend on reversible movement within the cell wall [9, $16,15,17]$

All streptococci maintain genes encoding the basic components needed for elaboration of a com pilus that is orthologous to the com competence pseudopilus of $B$. subtilis, and, like $B$. subtilis, regulate their expression to coincide with the development of competence for natural genetic transformation [39]. The comG and pilD operons, conserved among all competent Grampositives, comprise eight genes. Structural com pilus subunits include ComGC, the principal subunit called the "major pilin", and minor pilin subunits designated ComGD, ComGE, ComGF, and ComGG. ComGA is a cytosolic secretion ATPase; ComGB is a polytopic membrane protein; pilD, encoding the prepilin peptidase, is unlinked to the comG operon, but is coregulated with it during competence induction [39].

Only one Gram-positive competence pilus has thus far been directly observed as an external appendage. Electron microscopy and immunostaining directed against the ComGC pilin of Streptococcus pneumoniae (pneumococcus) revealed that competent cultures of this species specifically accumulate ComGC-containing pilus fragments, and that competent cells carry one or two pili with a typical type IV pilus structure, approximately $6 \mathrm{~nm}$ thick but 1000 or more $\mathrm{nm}$ long, clearly distinct from the paradigmatic $B$. subtilis pseudopilus [44]. A direct role for this pilus in DNA uptake is suggested by the observation that DNA co-purifies with pilus fragments and is found associated lengthwise with pilus fragments via EM analysis [44].

Although type IV competence pili of both Gram-negative and Gram-positive bacteria mediate DNA uptake, there are important differences between the competence pili in the Gram- 
71 respectively, whereas pneumococcal and other com pilus loci lack a retraction ATPase [21, 44].

72 Nonetheless, many pilus systems without a dedicated retraction ATPase still exhibit dynamic

73 retraction [21] and at least one extension ATPase, for the tad pilus, is known to be bifunctional,

74 promoting both pilus extension and retraction [27]. Thus, a major open question about the

75 pneumococcal competence pilus is whether this structure both dynamically extends and retracts.

76 Second, unlike V. cholerae, competent Gram-positive bacteria do not translocate DNA across an

77 outer membrane; they might instead use competence pili to bring DNA (via retraction) through

78 the thick cell wall for access to the DNA processing and transport machine. Thus, a second major

79 unanswered question is whether Gram-positive competence pili actively move DNA across the thick peptidoglycan barrier.

Because numerous type IV pili serve functions distinct from motility that nonetheless depend on retraction, our hypothesis was that, despite lacking an apparent retraction ATPase, the streptococcal competence pilus is a retractable organelle, and that, like other type IV pili, its subunits equilibrate, via extension/retraction cycles, with a pool of monomers in the membrane.

The pneumococcal competence pilus was previously visualized using a FLAG epitope-directed fluorescent antibody in fixed preparations [44]. However, the bulkiness of such a label moiety is likely to interfere with any retractive pilus activity in living bacteria. To obtain a more dynamic view of the pneumococcal competence pilus, we coupled the less bulky thiol-reactive fluorescent maleimide conjugate Alexa-Fluor 488 C5 maleimide (AF488-mal) directly to cysteine residues that we placed, by targeted mutagenesis, within the ComGC major pilin [26]. We report here that

91 the strategy labels extracellular pili and that these tagged competence pili are highly dynamic, participating in cycles of extrusion and retraction over timescales of seconds. We further provide evidence that this retraction is required for DNA uptake, consistent with the hypothesis that these pili act as fishing lines for DNA. 


\section{RESULTS}

Cys substitution mutants of S. pneumoniae. Pneumococcal type IV competence pili are long filamentous 6.4-nanometer-diameter appendages composed almost entirely of a single repeating pilin subunit, the major pilin ComGC, which lacks native cysteines [44, 54]. To label these structures, cysteine knock-in mutants of ComGC can be generated, which, if the incorporated cysteine is solvent accessible, would allow for subsequent labeling of pili with lowcompromises pilus function. Encouraged by the fact that a FLAG epitope placed at the C-terminus of ComGC does not interfere with transformation [44], indicating that other small alterations to the pilin structure might be tolerated as well, we designed and constructed nine distinct pneumococcal Cys-substituted comGC mutants, based on analysis of the ComGC subunit to pinpoint likely surface-exposed residues (Fig. 1 A-B). All of the new comGC-Cys substitution mutants have functional type IV competence pili, as evidenced by detectable rates of natural transformation

(Fig. 1C). Three transformed at rates indistinguishable from the parent, while the remaining six retained readily detectable but reduced rates of transformation. The substitutions with the highest

112 transformation rates were at serine residues S60 and S66 in the N-terminal alpha 1-C core domain, or at S74, in the adjacent alpha 2 region of the head domain [54]. Thus, although not all Cys replacements are neutral toward transformation, at least three innocuous positions are available for placement of a Cys thiol target for maleimide labeling. Most results reported here were obtained with SAD1671, carrying the ComGC ${ }^{\text {S66C }}$ substitution. 
120

121

122

123

124

125

126

127

128

129

130

131

132

133

134

135

136

137

138

139

140

141

pool of processed subunits during extrusion, while retraction reverses assembly, establishing an equilibrium between the pool of subunits in the membrane and subunits transiently incorporated in extended pili. Since the comG operon is expressed only in competent cells [39, 61], we reasoned that if ComG competence pili are retractile, AF488-mal tagging might best be done during an early part of a competence episode, when exposed pilin thiols would be available for reaction with the cell-impermeable maleimide reagent. After removal of unreacted dye, the accumulated AF488-tagged membrane pilin pool might continue to support further cycles of extrusion and retraction, which could be directly observed by fluorescence microscopy as dynamic pili.

Visualization of competent pneumococci labeled with AF488-mal according to this strategy would require satisfying several mutually incompatible conditions. For example, the optimal medium (chemically defined medium, CDM) for competence development includes a high level of cysteine, but cysteine quenches the maleimide reagent; and practical microscopy requires a dense cell suspension, but competence is optimal during exponential growth at low cell densities [30]. Finally, pneumococcal competence is regulated in part by an internal timer that shuts down competence expression after $\sim 30$ minutes $[45,52,75]$. Fortunately, the needed conditions can be satisfied separately but serially. Although late-log-phase or stationary-phase cells are poorly responsive to CSP [30], it was recently reported that efficient competence expression can be achieved at an artificially high cell density by collecting exponentially growing cells and simply resuspending them at a high density in fresh CDM medium [42, 43]. For this study, we took advantage of the stability of the competent state at $0-4{ }^{\circ} \mathrm{C}[70]$, to establish a labeling protocol that makes changes of medium by brief centrifugations in the cold.

Whereas competence typically reaches a maximum at $\sim 20$ min after addition of CSP [45, 61], in the adopted labeling protocol (Fig. S1A), exposure to CSP for 10 min at $37^{\circ} \mathrm{C}$ initiates competence gene expression; then 5 min at $37^{\circ} \mathrm{C}$ with AF488-mal in Cys-free CDM permits 
maleimide-Cys reactions as competence approaches a maximum; finally, the tagged competent cells are washed free of unreacted dye in the cold and then either imaged or exposed to donor DNA for 60 min during further incubation at $37^{\circ} \mathrm{C}$ to assess residual competence. Competence of a culture that had been processed through four wash steps in the cold to effect such treatment with AF488-mal dye was compared to that of a parallel culture with no added dye, and to a culture that followed the same temperature shifts while suspended in the same complete CDM medium, but without wash steps (Fig. S1B). Transformation of an undisturbed CDM culture with the 5-kb Nov $^{R}$ donor amplicon was typically $\sim 50 \%$; while the chilling steps of our protocol may reduce competence slightly (to $\sim 40 \%$ ), the additional washing steps did not reduce this yield further (Fig. S1B). While we did not determine the fraction of ComGC pilins that acquire the AF488 adduct under these conditions, the results indicate that the level of thiol modification achieved is well tolerated, with little or no effect on the fraction of cells that remain competent at the time of imaging. We conclude that this protocol yields an experimental population of AF488-mal-treated highly competent cells suitable for direct observation.

Specific AF488-mal labeling of ComGC pilin. For direct observation of competent cells, resuspended AF488-mal-treated cells were deposited on a pre-warmed CDM agarose pad, inverted over a cover-glass, and warmed on the stage of a Deltavision Elite microscope for fluorescence imaging. This approach achieved bright cell fluorescence, at a level that was 2-3fold higher in ComGC-Cys cells than in the identically treated parental strain lacking cysteine substitution, and that depended, for the ComGC-Cys mutant, on competence (CSP treatment) (Fig. 2). Thus, the majority of fluorescence signal from competent mutant cells is attributable specifically to the ComGC-Cys-AF488-mal adduct. The background fluorescence characteristic of the parental strain and the uninduced comCG-Cys mutant may reflect reaction of AF488-mal with native proteins presenting accessible thiols. Interestingly, this background label appears to be limited to the 'newer' surface of growing cells at the division plane (Fig. 2A), suggesting a 
170

171

172

174

175

176

177

178

179

180

181

182

183

184

185

186

187

188

189

maturation process that gradually exposes reactive peripheral thiol groups. For effective labeling of the competence pilus, the choice of maleimide conjugate and of Cys substitution position within ComGC are both critical (Fig. S2).

Inspection of Fig. 2A shows that in the comGC-Cys mutant, fluorescence signal was visible in the entire cellular periphery, consistent with our expectation for equilibration of ComGC from pili into the cell membrane, both newer and older. One or two bright fluorescent foci or extended appendages also appeared specifically in many competent Cys-AF488-tagged cells (Fig. 3 A1-A2), but the total fluorescence signal from such cells was indistinguishable from the fluorescence signal from cells that had neither a focus nor appendage (Fig. 3 B1-B3).The structure of these foci was not resolved, but we speculate that they may reflect a concentration ComG pilins near the ComGB base upon which pili are assembled, or may represent short or preemergent pili that are not resolved by our imaging conditions. To gain some perspective on the geography of the bright foci, a cell coordinate system was adopted to map the axial positions of foci (Fig. S3-S4 and Fig. 3C1). The foci were not randomly positioned, but were located predominately at the medial zone where cell wall growth occurs, and were rarely polar or subpolar (Fig. 3C2). We mapped the apparent bases of the extended appendages, which could be competent pili, found in competent comGC-Cys cells (Fig. S5-S6) using the same coordinate system as used above for foci. Remarkably, the apparent appendage base mapped, like foci, predominantly to the medial growth zone (Fig. 3C3), although polar appendages were also occasionally apparent.

AF488-mal-labeled protrusions extend and retract on 1-10-second timescales specifically from competent Cys-substituted cells. Noticing occasional apparently filamentous extensions in the images as described above, we searched for transient pilus-like structures associated with comGC-Cys competent cells, using time-lapse images of CSP-treated SAD1671 cells on the CDM agarose pads, at 2-sec intervals for a 60-sec window. Remarkably, many cells 
exhibited transient filamentous protrusions (Movie S1-S4), which often emerged near the medial growth zone (Fig. 3C3) and typically disappeared, apparently by retraction, within 5-10 seconds (Fig. 4 A1-A2), sometimes reappearing from the same cell (Fig. 4B). Similar but static protrusions were also occasionally observed (Movie S5-S7). Pili were typically approximately $500 \mathrm{~nm}$ long, but occasionally over 1 micron (Fig. 4C1). Extrusion and retraction rates were highly variable from cell to cell and from time to time within a single extrusion episode (Fig. 4C1). However, retraction was regularly faster than extrusion (Fig. 4 C1-C2, Movie S8-S15) and a variable extrusion trajectory was typically followed by rapid retraction (Fig. 4C2). Fluorescent protrusions were absent from parental cells treated with AF488mal in parallel, and from non-competent SAD1671 cultures (Fig. 4D). Because they depended both on the ComGC-Cys substitution and on CSP treatment, we interpret these mobile extended structures as transiently extended comGC-Cys type IV pili, and conclude that the extracellular pili and pilus fragments imaged previously in fixed material from competent cultures $[44,54]$ are not static appendages, but represent actively mobile retractable filaments, which had been 'frozen' by the imaging methodology but are here revealed as such by live imaging. Since we found that the pilus base localized near midcell zone (Fig. 3C2), it is puzzling that the predominant midcell location of pili seen here contrasts with the [44] report that in electron micrographs of competent cells, com pili displayed no preferred location at all [44] . The discrepancy might best be resolved by applying both mapping tools in parallel to a single competent culture.

\section{Both transformation and retraction are blocked by neutravidin in the ComGC-Cys mutant.}

We reasoned that the retractable competence-specific pilus of pneumococcus might function like the type IV competence pilus of the Gram-negative pathogen, Vibrio cholerae, despite the long evolutionary distance between Gram-positive and Gram-negative bacteria, and that retraction of this pilus could be similarly important for DNA uptake. To test this possibility more directly, we asked whether blocking pilus retraction by attaching a bulky adduct to the comGC-Cys pilin would 
affect DNA uptake. For this purpose, a biotin-maleimide reagent (biotin-mal) was used (along with AF488-mal at a ratio of 1:5) to tag the ComGC pilins. As expected, the competition by the nonbut the biotin-tagged cells exhibited unaffected transformation yields and displayed mobile pili

(Fig. 5 A2 and D), which is not surprising because biotin is a low-MW adduct that similarly does not affect the function of other T4P [25]. To attach a much bulkier adduct, the biotin-mal tagged cells were then exposed to neutravidin, a 60,000-dalton protein with high affinity for biotin [47]. The added neutravidin reduced transformation by five-fold, but had no effect whatsoever on parallel similarly treated competent parental strain cells, which lack ComGC thiols (Fig. 5D) . Imaging of the biotin/neutravidin-treated cells confirmed that pilus retraction was strongly inhibited by the bulky adduct (Fig. 5A3), indicating an important role of pilus retraction in DNA uptake. Blockage of retraction was evidenced by a decrease in observable dynamic pili, an increase in static pili, and by appearance of a new class of cells that contained a large bolus of extracellular fluorescent material (Fig. 5 A3-A4, and 5C). This bolus contained a significantly higher relative fluorescence level than a focus or a pilus (Fig. S16). It may represent a tangle of pilus fibers, cross-linked by the neutravidin molecules. Indeed, because neutravidin is a tetradentate biotinbinding protein, and biotin-mal-tagged pili would carry many biotin residues, it can be expected that retraction would be blocked by formation of intra-pilus cross-links as well as by the simple steric hindrance introduced by the bulky neutravidin adducts. Because neutravidin inhibited transformation specifically of biotin-tagged cells and caused accumulation of external pili, we conclude that retraction is important for transformation, and further hypothesize that the Gram-

241 positive type IV competence pilus transports DNA to and through the cell wall via its dynamic 242 retraction. 
245 the Cy5 fluorophore, which is incompatible with trans-membrane transport to the cytoplasm [6],

246 but is readily tracked in the extracellular space. Depositing the labeled lambda DNA with

247 competent cells on agarose pads allowed use of two-color epifluorescence to image and count

248 both cells and DNA (Fig. 6 A-B). The DNA was readily visualized as individual molecules either

249 as compact bundles or, rarely, as extended molecules. While cells were immobile on the agarose

250 pads, the lambda DNA molecules roamed the pad, by random Brownian motion (Movie S18-

251 S19). Remarkably, DNA molecules were observed as transiently captured at the surface of 10-

$25220 \%$ of cells. This capture occurred both with the ComGC-Cys mutant and with unsubstituted

253 parent strain cells (Fig. 6 B1-B2), but not in either strain absent CSP treatment (Fig. 6C). To

254 explore further the specificity of this capture, we mapped the subcellular location of captured DNA

255 by mapping its apparent ' attachment' site using the same approach as described in Fig. $\mathbf{3}$ for foci

256 and pili. Attachment predominantly at midcell (Fig. 6D) is consistent with a role for competence

257 pili in facilitating the approach of nearby DNA to the surface of competent cells. 


\section{DISCUSSION}

260

261

262

263

264

265

266

267

268

269

270

271

272

273

274

275

276

277

278

279

280

281

282

283

Visualization of a mobile pneumococcal type IV competence pilus fills a gap in understanding DNA uptake in pneumococcus. Analogous to the challenge of the 'last mile' in domestic package delivery, the 'last micron' has been a persistent puzzle in describing access of competent Gram-positive bacteria to donor DNA. In the streptococci, the natural source of such DNA is understood to be lytic attack on a noncompetent cell by a nearby competent cell. Once a loop of DNA contacts a membrane-localized transport complex; endonucleolytic incision to create a double-strand break is followed by transport of one strand linearly across the membrane concomitant with reduction of the complementary strand to oligonucleotide products, by EndA. Various roles for a type IV competence pilus have been proposed in the 'last micron', where released DNA nears the cell periphery, passes the capsule, if present, crosses the cell wall peptidoglycan, and gains access to the periplasmic surface of the trans-membrane transport complex [64]. One possibility was that the pilus simply provides a static adhesin that accumulates DNA in the vicinity of the competent cell; others envisaged an actively retractable pilus that serves as a molecular grapnel to conduct DNA toward the cell, through the capsule, and across the cell wall either through the same opening that accommodates pilus extrusion and retraction of through an adjacent opening. To distinguish directly between static and active roles, we arranged for livecell imaging of the pneumococcal competence pilus. The images displayed here raise serious doubt as to a purely static adhesin, while showing behavior much better suited to a grapnel-like role.

Until now, the short competence (pseudo)pilus of $B$. subtilis has offered an apparent paradigm for type IV competence pili in the Gram-positives. The ComG/PilD operons, conserved among all competent Gram-positives, comprise just eight genes. Altogether, this com pilus gene system is considerably smaller than the Gram-negative type IV competence pilus systems, where additional apparatus is devoted to pilus passage across the outer membrane $[10,35]$. It would 
not have been surprising if the pneumococcal competence pilus acted similarly to the $B$. subtilis pseudopilus. Both long and short competence pili are known in Gram-negative species; the long Gram-negative competence pilus of Vibrio cholerae is retractable and brings DNA to the competent cell after binding DNA at a distance from the cell surface, via its tip. But mobility of the Gram-negative short (pseudopilus) competence pilus remains an inference, lacking direct evidence. The present observations of mobile long competence pili in $S$. pneumoniae now suggest that Gram-positive competence pili similarly occur in alternative forms. Strong conservation of the comG/PilD genes across all streptococci suggests that the mobile long com pilus of pneumococcus may be a common or universal feature of the competent state across the genus Streptococcus. It also suggests that long retractable Gram-positive competence pili may be found in multiple genera, as are their Gram-negative relatives.

It is interesting to consider whether the two pilus forms may solve different biological challenges. Elementary physical considerations suggest that a long reversibly extendable pilus with a DNA-binding tip could be especially valuable for a species, such as pneumococcus, that is often enrobed in a viscous negatively charged carbohydrate capsule that may be up to $1000 \mathrm{~nm}$ thick. If the capsule confronts extracellular DNA with both charge repulsion and a macromolecular impediment to diffusion, an active capsule-penetrating pilus might be doubly favorable, if it could usher DNA through not only the capsule but also through the thick peptidoglycan cell wall.

Visualization of motility of the pneumococcal type IV competence pili leaves open many questions about the mechanism of DNA uptake. Major challenges remain for defining the path of DNA into naturally competent cells [64]. Does DNA accompany the pilus fiber across three barriers? Or follow the retracting pilus thru a residual pore? Or benefit from access to yet another, still unknown 'pore'? Does EndA have any role in untangling potential DNA knots, or is that managed entirely by the moving pilus, prior to its passing across the cell wall? Reversible extension of the pneumococcal type IV competence pilus draws attention to the lack of an 
apparent retraction ATPase in all Gram-positive type IV competence operons [44]. One solution proposed is that ATPase activity of ComFA might supply the missing retraction ATPase [23]. However, pneumococcal ComFA has been isolated and biochemically characterized as a ssDNAbinding protein with ssDNA-dependent ATPase activity that interacts with itself, DprA, and

313 ComFC, but not ComGA [22]. It would be surprising of such a small protein had a second, 314 independent function, in pilus retraction. An attractive alternative is that the single ATPase 315 uniformly associated with comG pilus loci acts as a reversible ATPase, much like CpaF, the single ATPase that powers motion of tad type IV pili during both extrusion and retraction in Caulobacter crescentus [27].

A surprising behavior of the pneumococcal competence pilus was that avidin-complexed pili regularly formed large pilus tangles consuming much of the available labeled pilin monomer. The tetravalent avidin adduct may be expected to act as an extracellular rachet that prevents pilus back-sliding during extrusion but allows continued extrusion unhindered; this could supply an ever-growing pilus of extraordinary size, attached to a single point of secretion. If tangles contain the equivalent of 2-3 microns of pilus, apparently extruded from a single site, this indicates that extrusion is not inherently limited to the typical $0.5-1$ micron length, but is usually interrupted by an (unknows) length-restricting or retraction-triggering mechanism. In Vibrio cholerae, no similar tangles were noted on cells treated with avidin to block retraction. Because tangles of this size 327 were not found for $V$. cholerae competence pili after blockage with avidin, we speculate that the pneumococcal com pili are more flexible that those of $V$. cholerae. Indeed, inspection of live video movies of moving pili and of electron micrographs of fixed pili shows noticeably more flexibility in the com pili from pneumococcus that for the Vibrio competence pilus $[25,44,55]$.

The roles of minor pilins are unknown. Type IV competence pili are assembled as a threestart helical fiber generated by successive incorporation of pilin subunits from a membrane pool, but subunit composition and placement within the fiber are not yet well defined. Within each fiber, 
(E5) and the N-terminal amino group of the previously added pilin [20, 50, 58]. A single minor pilin lacking the conserved E5 is typical of type IV competence pili, where this subunit may be the first pilin added to the fiber and, therefore, does not require a glutamate to form a salt bridge. Mutants individually lacking each minor pneumococcal pilin are defective in transformation and pilus assembly, establishing that all four minor pilins are needed for pilus assembly [57]. Oliviera also reported observing a complex of all the minor pilins and hypothesized that a complex of minor pilins is linked to the pilus tip through the largest minor pilin, ComGG. We have not mapped DNA binding sites on the pneumococcal competence pilus; but Laurenceau et al [44] observed sideby-side pilus-DNA association in the EM, and a tip complex might be an alternative binding site. Finally, the role of the pilus might be different in Gram-positives, where no outer membrane pore restricts the dimensions of an incoming complex of DNA and pilus. The path of DNA through the thick peptidoglycan cell wall may accommodate the complex more easily, perhaps including the side-by-side mode of association visualized in EM micrographs by Laurenceau et al [44].

In several Gram-negative competent species, DNA passes through the outer membrane with participation of the periplasmic soluble protein ComEA, which acts as an entry rachet that impedes retrograde movement of DNA [31]. The rachet quickly accumulates periplasmic dsDNA, which is separately subject to nucleolytic transfer across the inner membrane. In pneumococcus and Bacillus, ComEA is not soluble, but localizes to the outer surface of the cell membrane, and is required for DNA uptake; it is not known whether it also acts as a rachet to facilitate or drive DNA movement through the cell wall into the periplasm similarly to DNA uptake in competent Gram-negative species. However, in pneumosoccus ComEA does assemble at a single focus in competent cells that recruits EndA from it normal locations throughout the membrane to a site near the site of DNA uptake [3]. The preferential mid-cell localization of ComGC foci and pili raises the question of whether they, too, are recruited by ComEA. If tDNA passes through the same wall opening as the competence pilus, colocalization of the pilus and transport proteins would potentially facilitate transfer of DNA from one to the other. However, it remains unclear whether 
361 pilus-dependent transport and trans-membrane transport are spatially or temporally coordinated

362 events.

363 With the discovery that expression of $\mathrm{CbpD}$, LytA, and competence bacteriocin-like 364 peptides are linked directly to competence regulation, and with demonstration that these products 365 increase the efficiency of transformation in mixed-cell cultures dramatically (1000-fold) [36], it 366 became reasonable to appreciate genetic transformation as reflecting a complex coordinated 367 system of gene transfer from one living cell to another. Specificity in the choice of victim cell is 368 enhanced by species-specificity of CbpD's peptidoglycan preference, the principal lysin. The rate 369 of that transfer appears to be further enhanced by the retractable DNA binding pilus described 370 here, either by bringing the competent cells toward the DNA mass released upon lysis of a target, 371 or by bringing that DNA toward the competent cell, or both. Repetitious probing by a competence

372 pilus from a single competent cell might bring multiple separate bights of the genome from a 373 recently lysed victim to the DNA transport machine. Such a combination of DNA 374 processing/uptake events could explain the wide scattering of recombination tracts emerging in 375 transformants produced by 2-cell interactions [19, 43]. 


\section{Experimental procedures}

377

378

379

380

381

382

383

384

385

386

387

388

389

390

391

392

393

394

395

396

397

398

399

Bacterial strains and media. All pneumococcal strains used in this study were derived from the Rx1 derivative CP2137 (hex malM511 str-1 bgl-1 $\Delta$ comA $\Delta c p s$ ssbB-::[pEVP3]::ssbB ${ }^{+}$; Hex $\mathrm{Mal}^{-} \mathrm{ComA}^{-} \mathrm{Cps}^{-} \mathrm{SsbB}{ }^{+} ; \mathrm{Sm}^{\mathrm{R}} \mathrm{Cm}^{\mathrm{R}}$ low a-galactosidase background) [73]. For cell stocks, strains were grown to an optical density of 0.3 at $550 \mathrm{~nm}\left(\mathrm{OD}_{550}=0.3\right)$ in $12 \mathrm{~mL}$ of Todd Hewitt Broth (Becton Dickinson) with $2 \%$ yeast extract (Becton Dickinson) (THY), mixed with glycerol for a final concentration of $14 \%$, and stored at $-80{ }^{\circ} \mathrm{C}$. CDM medium was always prepared according to Chang et al [14], but with addition of a $1 \%$ supplement of CAT medium [73]. When cysteine was omitted from the standard CDM formulation, the medium is denominated CDM-Cys.

Reagents. Alexa Fluor 488 Malemide (AF488), Alexa Fluor 594 Malemide (AF594), or Alexa Fluor 647 Malemide (AF647) (Thermo Fisher Scientific) was dissolved in dimethylsulfoxide (DMSO) (Invitrogen) at $5 \mathrm{mg} \mathrm{mL}^{-1}, 5-\mu \mathrm{L}$ aliquoted, and stored at $-20{ }^{\circ} \mathrm{C}$. Biotin-mal (Thermo Fisher Scientific) was dissolved in DMSO at a final concentration of $5 \mathrm{mg} \mathrm{mL}^{-1}$ and sterile-filtered before 20- $\mu \mathrm{L}$ aliquots were stored at $-20^{\circ} \mathrm{C}$. Neutravidin protein (Thermo Fisher Scientific) was dissolved in distilled water at of $33 \mathrm{mg} \mathrm{mL} \mathrm{m}^{-1}$, sterile-filtered, $10-\mu \mathrm{L}$ aliquoted, and stored at $-80{ }^{\circ} \mathrm{C}$. Fluorophores were prepared and stored with limited light exposure. Lambda DNA (New England Biolabs) was labelled with Cy5 by following manufacture's protocol (Mirus Label IT Nucleic Acid Labeling Kit Cy5), diluted to $80 \mu \mathrm{gL}^{-1}$ in TE buffer, aliquoted, and stored at $-20{ }^{\circ} \mathrm{C}$.

Inducer cocktail. CSP-1 (NeoBiolab) [67] was dissolved in distilled water at $0.1 \mathrm{mg} / \mathrm{ml}$, filtered (0.2 $\mu \mathrm{m}$ filter Sartorius), $1-\mathrm{mL}$ aliquoted, and stored at $-20^{\circ} \mathrm{C}$. Bovine serum albumin (BSA) (Gold Biotechnology) was dissolved at $4 \%(w / v)$ in distilled water, sterile-filtered, and stored at $4{ }^{\circ} \mathrm{C}$. $\mathrm{CaCl}_{2}$ solid was dissolved in distilled water at $0.1 \mathrm{~mol} \mathrm{~L}^{-1}$, autoclaved, and stored at room temperature. An inducer cocktail containing $4 \mu \mathrm{gL}^{-1} \mathrm{CSP}-1,0.008 \% \mathrm{BSA}$, and $1 \mathrm{mM} \mathrm{CaCl}$ in CDM was prepared fresh before each experiment. 
Precompetent cells. Frozen stocks were diluted [1:40] in $12 \mathrm{~mL}$ of either THY or sterile-filtered $\mathrm{CDM}$ and maintained at $37^{\circ} \mathrm{C}$ until reaching an $\mathrm{OD}_{550}$ of 0.3 . The cultures were then chilled on ice for 15 minutes, centrifuged at 7000 RPM for 7 min at $4{ }^{\circ} \mathrm{C}$ (Eppendorf model 5804R). The supernatant was discarded, and the cell pellets were resuspended in cold THY or CDM at the indicated OD, and maintained on ice until needed. fresh CDM for an OD of 2. A 200- $\mu \mathrm{L}$ portion was then mixed 1:1 with inducer and incubated for 10 minutes at $37^{\circ} \mathrm{C}$ to activate competence. The culture was chilled on ice for 2 minutes, centrifuged at 7000 RPM for 4 minutes, and resuspended in cold CDM-cys. This step was repeated twice before labeling with $50 \mu \mathrm{g} \mathrm{mL} \mathrm{L}^{-1} \mathrm{AF} 488-\mathrm{mal}$ for 5 minutes at $37^{\circ} \mathrm{C}$. Labeled cells were then centrifuged in the cold, washed twice in CDM, and resuspended in fresh CDM before 412 imaging. To image cells and lambda DNA interaction, Cy5-labelled DNA was 10-fold diluted in 413 CDM and mixed with 3 vols AF488-mal labeled cells before imaging. To obstruct pilus retraction, 414 the indicated strains were co-labelled with $25 \mu \mathrm{g} \mathrm{mL}^{-1}$ of AF488-mal and $125 \mu \mathrm{gL}^{-1}$ of biotin415 mal for 10 minutes at $37^{\circ} \mathrm{C}$ before washing twice with CDM. $4.2 \mu \mathrm{L}$ of $33 \mathrm{mg} \mathrm{mL}^{-1}$ Neutravidin was 416 added to the $100 \mu \mathrm{L}$ washed cells at $1.32 \mathrm{mg} \mathrm{mL}^{-1}$ and incubated for 10 minutes on ice before 417 imaging.

Transformation assay. To assay competence of comGC-Cys mutant strains, each frozen stock was diluted, grown, centrifuged, and resuspended in THY for an OD of 2 or 0.02 . The cell cultures were then mixed in 1:1 ratio with the inducer cocktail for activation of competence, followed by 421 addition of $160 \mathrm{ng} \mathrm{mL}^{-1} \mathrm{Nov}^{\mathrm{R}}$ DNA and incubation for an hour at $37{ }^{\circ} \mathrm{C}$. The resulting cultures 422 were serially diluted and plated in soft agar as described [53] with the fourth layer containing 10 $423 \mu \mathrm{g} \mathrm{mL}^{-1}$ Novobiocin for selection, or THY agar for total CFU. Plates were incubated at $37^{\circ} \mathrm{C}$ for at 
least 16 hours before counting colonies. Transformation efficiency is defined as the number of Nov $^{R}$ transformants divided by the total viable CFU.

To determine the effect of AF488-mal protocol on competence (Fig. S1B), the strains were grown in CDM until an OD of 0.3 , centrifuged, and resuspended in fresh CDM. Three cultures were prepared by mixing 1:1 ratio of cells and inducer and incubated for 10 minutes. Two of the cultures went through the labeling protocol, without and without AF488-mal added. The other culture was a positive control that followed the temperature sequences of the labeling protocol without any exchanges of medium or centrifugation. After the final wash with CDM in the labeling protocol, a saturating amount of $\mathrm{Nov}^{\mathrm{R}} \mathrm{DNA}\left(540 \mathrm{ng} \mathrm{mL}^{-1}\right)$ was added to all cultures and incubated for an hour at $37^{\circ} \mathrm{C}$ before plating for $\mathrm{Nov}^{\mathrm{R}}$ transformants.

To observe the effect of Neutravidin (Fig. 5D), the indicated strains were grown in CDM, centrifuged, and resuspended in fresh CDM. Three cultures were prepared by mixing 1:1 ratio of cells and inducer and incubated for 10 minutes. Two of the cultures were co-labelled with $25 \mu \mathrm{g}$ $\mathrm{mL}^{-1}$ of AF488-mal and $125 \mu \mathrm{g} \mathrm{mL}^{-1}$ of biotin-mal for 10 minutes and the other culture was labelled with only $25 \mu \mathrm{g} \mathrm{mL}^{-1}$ of AF488-mal for 10 minutes. After the last washing with CDM, NeutrAvidin (1.32 $\mathrm{mg} \mathrm{mL}^{-1}$ ) was added to one of the co-labelled cultures. All cultures were maintained on ice for 10 minutes before $160 \mathrm{ng} \mathrm{mL}^{-1}$ of $\mathrm{Nov}^{\mathrm{R}}$ DNA was added to each culture. After 60 min at 37 ${ }^{\circ} \mathrm{C}$, cultures were further diluted in CAT and plated for Nov selection and CFU counts.

Imaging and quantitative analysis. All imaging was done on 1\% CDM agarose pads with a Deltavision Elite Deconvolution Microscope system (GE Healthcare Biosciences) with an environmental chamber maintained at $37^{\circ} \mathrm{C}$ with a beaker of water to maintain humidity. Cell bodies were imaged using a differential interference contrast (DIC) module, whereas fluorescence was imaged using fluorescence microscopy on a Olympus IX71 microscope with Plan Apo 100X oil immersion objective, a filter set including FITC, Cy5, and mCherry filter, PCO Edge CMOS camera, and softWoRx imaging software. Cy5 labelled DNA was imaged using a Cy5 filter. Time- 
lapse images were acquired for 1-minute at 2-second intervals, with exposures of 150-200 msec at a light intensity of $5-10 \%$ for the fluorescent filters, $15 \mathrm{~ms}$ and $32 \%$ of exposure and light intensity, respectively, for DIC. For visualization, each raw image was deconvolved using built-in softWoRx imaging software, normalized for background, and corrected for photobleaching using ImageJ. For quantification, the 16-bit image at time 0 of the time-lapse imaging series was extracted and subtracted for background before measuring integrated fluorescence signal. Colormap maps were constructed in MATLAB using 16-bit deconvolved images (scale 0-255). To determine pilus maximal length, cells that had already begun retraction when imaging began or reached maximum length at the last frame were excluded from the analysis. For extrusion rate calculation, only cells with a full cycle of pilus extrusion and retraction during 1-min time-lapse imaging were used for the analysis. For retraction rate calculation, only pili retracted within a 1min window were use for the calculation. Extrusion and retraction rate were calculated as the change in pilus length over time. detection. Dipplococcus cell center re-adjustment is shown in Fig. S3. Cells with a pilus were first pre-processed using imageJ before maxima detection in microbeJ (Fig. S5). Heatmap distributions were created using MicrobeJ. Absolute coordinate values were taken for the distribution histogram.

Statistics. Significance between multiple groups $(>3)$ was calculated using One-way ANOVA with 470 Tukey's post-hoc analysis on Prism 9 software.

471 Cysteine substitution mutagenesis. Relative surface accessibility (RSA) scores of all amino 472 acids in ComGC sequence [54] were analyzed by Net-SurfP [60] to determine the substitutions 473 position. ComGC structure model (Fig. 1) was generated from the protein sequence using Phyre2 
474 [38] (see also Protein Data Bank (PDB) 5NCA) and processed for visualization using Chimera 475 software [62].

$476 \quad$ Mutant constructs for Cys mutations were generated via splicing-by-overlap extension

477 (SOE) PCR as previously described [18]. The upstream region of homology (UP arm; amplified

478 with F1/R1 primers) was stitched to the downstream region of homology (DOWN arm; amplified

479 with F2/R2 primers). Point mutations to generate the Cys mutations were incorporated into the

480 R1/F2 primers. All mutant constructs were introduced into CP2137 by natural transformation.

481 Output colonies were screened by colony mismatch amplification (MAMA) assay PCR [12] for the 482 presence of the desired point mutations and confirmed by sequencing. See Table 1 for a list of 483 primers used to generate mutant constructs in this study. 
Table 1. Primer oligonucleotides used in mutagenesis

\begin{tabular}{|c|c|c|}
\hline $\begin{array}{c}\text { Primer } \\
\text { Name }\end{array}$ & Sequence $\left(5^{\prime} \rightarrow 3^{\prime}\right)$ & Description \\
\hline CE1 & GTATCGTGTTATAGAAATGTACGGAGATTTTTGAACC & cglC F1 \\
\hline CE14 & GCATCTTCATTCTTTTCTAAacaATAAAGTTCTGCCTGGCTTT & $\begin{array}{l}\text { cglC S66C } \\
\text { R1 }\end{array}$ \\
\hline CE13 & AAAGCCAGGCAGAACTTTATtgtTTAGAAAAGAATGAAGATGC & $\begin{array}{l}c g / C \text { S66C } \\
\text { F2 }\end{array}$ \\
\hline CE2 & CTTGGACATTCTCTAGTAAATAGGTATAAGCTTGT & cg/C R2 \\
\hline CE15 & CCAGGCAGAACTTTATTGT & $\begin{array}{l}\text { cg/C S66C } \\
\text { detect F }\end{array}$ \\
\hline CE3 & AACTGTCAACTTTTTGACTGC & cglC detect $\mathrm{R}$ \\
\hline CE5 & ACAAAGAGCAAGAAAAGCACACAGATAATCAGCAAGACCACCA & $\begin{array}{l}c g / C \text { S29C } \\
\mathrm{R} 1\end{array}$ \\
\hline CE4 & TGGTGGTCTTGCTGATTATCTGTGTGCTTTTCTTGCTCTTTGT & $\begin{array}{l}\text { cglC S29C } \\
\text { F2 }\end{array}$ \\
\hline CE6 & GGTCTTGCTGATTATCTGT & $\begin{array}{l}\text { cg/C S29C } \\
\text { detect F }\end{array}$ \\
\hline CE8 & TTGACTGCTTCTTTTTTGCTTACACAGATTAGGTACAAAGAGCA & $\begin{array}{l}\text { cg/C T40C } \\
\text { R1 }\end{array}$ \\
\hline CE7 & TGCTCTTTGTACCTAATCTGTGTAAGCAAAAAGAAGCAGTCAA & $\begin{array}{l}\text { cglC T40C } \\
\text { F2 }\end{array}$ \\
\hline CE9 & CTTTGTACCTAATCTGTGT & $\begin{array}{l}c g / C \text { T } 40 C \\
\text { detect } F\end{array}$ \\
\hline CE11 & AAGCTATAAAGTTCTGCCTGACATTCCACCACCTTAACAACAG & $\begin{array}{l}\text { cglC S60C } \\
\text { R1 }\end{array}$ \\
\hline CE10 & CTGTTGTTAAGGTGGTGGAATGTCAGGCAGAACTTTATAGCTT & $\begin{array}{l}\mathrm{cg} / \mathrm{C} \text { S60C } \\
\text { F2 }\end{array}$ \\
\hline CE12 & TGTTAAGGTGGTGGAATGT & $\begin{array}{l}\text { gg/C S60C } \\
\text { detect F }\end{array}$ \\
\hline CE17 & TCTGCTTGTAACTTTCTTAGACAAGCATCTTCATTCTTTTCTA & $\begin{array}{l}\text { cglC S74C } \\
\text { R1 }\end{array}$ \\
\hline CE16 & TAGAAAAGAATGAAGATGCTTGTCTAAGAAAGTTACAAGCAGA & $\begin{array}{l}\text { cglC S74C } \\
\text { F2 }\end{array}$ \\
\hline CE18 & AAAGAATGAAGATGCTTGT & $\begin{array}{l}\text { cglC S74C } \\
\text { detect F }\end{array}$ \\
\hline CE20 & TCTTCCGTGATGCGTCCATCACATTGTAACTTTCTTAGGCTAG & $\begin{array}{l}\text { cglC A80C } \\
\text { R1 }\end{array}$ \\
\hline CE19 & CTAGCCTAAGAAAGTTACAATGTGATGGACGCATCACGGAAGA & $\begin{array}{l}c g / C \text { A80C } \\
\text { F2 }\end{array}$ \\
\hline CE21 & GCCTAAGAAAGTTACAATGT & $\begin{array}{l}\text { cglC A80C } \\
\text { detect F }\end{array}$ \\
\hline CE23 & TAAGCTTTAGCCTGTTCTTCACAGATGCGTCCATCTGCTTGTA & $\begin{array}{l}\mathrm{cglC} \text { T85C } \\
\mathrm{R} 1\end{array}$ \\
\hline CE22 & TACAAGCAGATGGACGCATCTGTGAAGAACAGGCTAAAGCTTA & $\begin{array}{l}\mathrm{cglC} \text { T } 85 \mathrm{C} \\
\mathrm{F} 2\end{array}$ \\
\hline CE24 & AGCAGATGGACGCATCTGT & $\begin{array}{l}\text { cg/C T85C } \\
\text { detect F }\end{array}$ \\
\hline
\end{tabular}




\begin{tabular}{|c|c|c|}
\hline CE29 & CATGGTAAAGGCCttaATCACAGACTTTACGATTTGCTCCTC & $\begin{array}{l}\text { cglC N107C } \\
\mathrm{R} 1\end{array}$ \\
\hline CE28 & GAGGAGCAAATCGTAAAGTCTGTGATtaaGGCCTTTACCATG & $\begin{array}{l}\text { cglC N107C } \\
\text { F2 }\end{array}$ \\
\hline CE30 & GAGCAAATCGTAAAGTCGT & $\begin{array}{l}\text { cglC N107C } \\
\text { detect F }\end{array}$ \\
\hline CE32 & CCAGCATGGTAAAGGCCttaACAATTGACTTTACGATTTGCT & $\begin{array}{l}\text { cglC D108C } \\
\text { R1 }\end{array}$ \\
\hline CE31 & GAGCAAATCGTAAAGTCAATTGTtaaGGCCTTTACCATGCTGG & $\begin{array}{l}c g / C \mathrm{D} 108 \mathrm{C} \\
\mathrm{F} 2\end{array}$ \\
\hline CE33 & CAAATCGTAAAGTCAATTG & $\begin{array}{l}\text { cglC D108C } \\
\text { detect F }\end{array}$ \\
\hline
\end{tabular}

Table 2. Cysteine substitution mutants used in this study

\begin{tabular}{|c|c|}
\hline Replacement & Strain \\
\hline S29C & SAD1668 \\
\hline T40C & SAD 1669 \\
\hline S60C & SAD 1670 \\
\hline S66C & SAD 1671 \\
\hline S74C & SAD 1672 \\
\hline A80C & TND 401 \\
\hline D108C & TND 402 \\
\hline T85C & TND 403 \\
\hline N107C & TND 404 \\
\hline
\end{tabular}

Acknowledgements. The authors gratefully acknowledge Xin Wang of Dr. David Stone of microscopy training and consultation. 

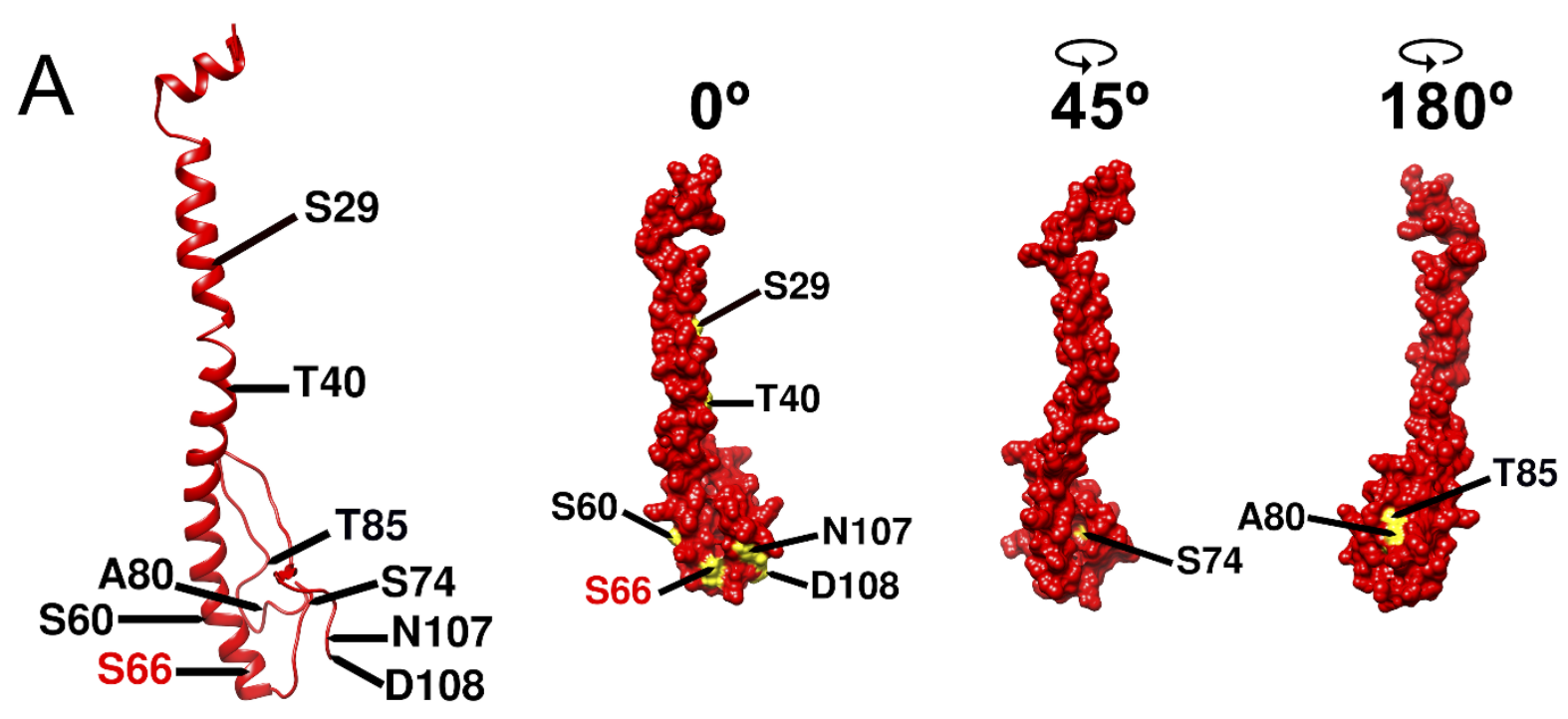

$\begin{array}{ccc}\text { B } & \begin{array}{c}\text { Position } \\ \text { mutated }\end{array} & \begin{array}{c}\text { RSA } \\ \text { score }\end{array} \\ \text { S29 } & 0.44 \\ \text { T40 } & 0.43 \\ \text { S60 } & 0.5 \\ \text { S66 } & 0.17 \\ \text { S74 } & 0.31 \\ \text { A80 } & 0.74 \\ \text { D108 } & 0.94 \\ \text { T85 } & 0.48 \\ \text { N107 } & 0.91\end{array}$

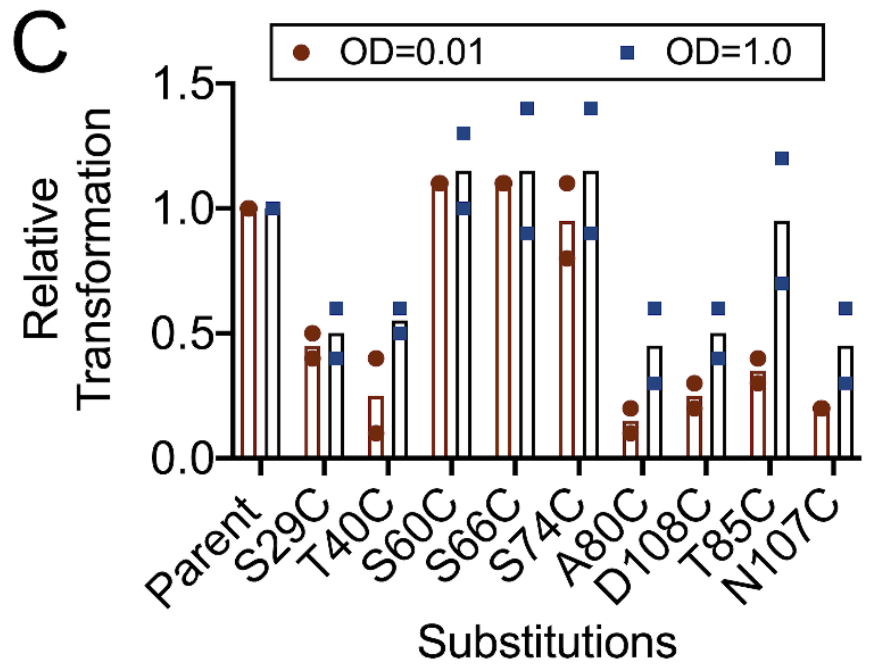

Figure 1. Cysteine substitution mutations at ComGC allow transformation. A) ComGC structure model. Red, cysteine replacement characterized in this paper. B) Relative surface accessibility (RSA) score of 9 cysteine substitution sites. C) Transformation efficiency of 9 ComGC-Cys mutants. Each strain was grown in THY to OD of 0.3 , centrifuged, and resuspended in fresh THY at OD 2.0 or 0.02 . Inducer was added 1:1 to each culture (OD 1.0 or 0.01 ), with 160 ng Nov ${ }^{R}$ DNA per $\mathrm{mL}$. After $60 \mathrm{~min}$ at $37^{\circ} \mathrm{C}$, they were diluted and plated for selection. Relative transformation is calculated as a ratio of the mutant transformation efficiency to that of the parent strain. Data from each experiment $(O D=0.01$ and $O D=1)$ are shown as mean and individual data points from two independent biological replicates. 


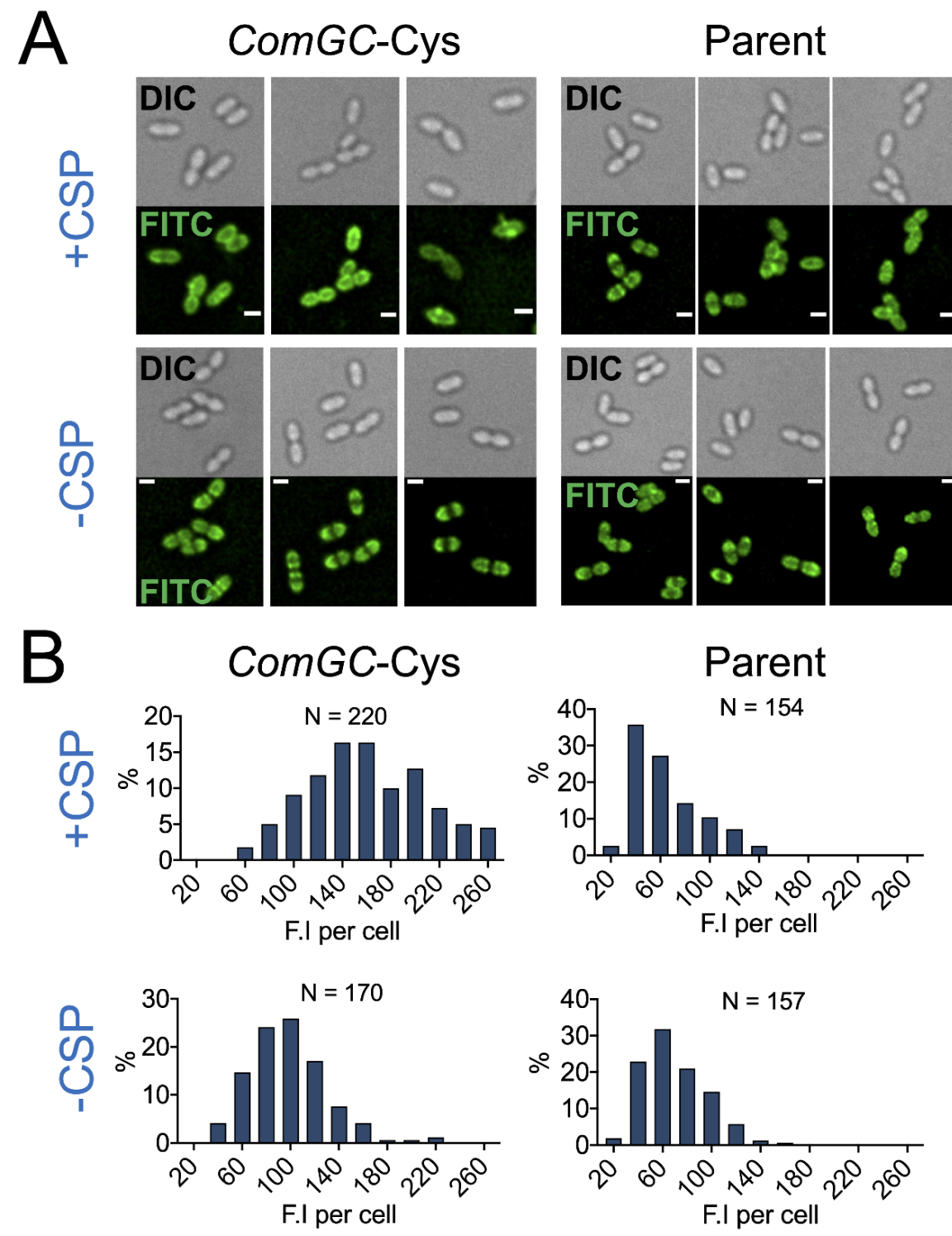

Figure 2. Comparison of AF488-mal fluorescence signals from competent vs. noncompetent comGC-Cys mutant or parent strains. A) Representative static deconvolved images of competent (+CSP) and non-competent (-CSP) ComGC-Cys and parent cells labeled with AF488-mal in accord with the protocol of Fig. S1. Top panels, cell body imaged using differential interference contrast (DIC); bottom panels, fluorescent signal imaged using a FITC filter. Scale bars, $1 \mu \mathrm{m}$. B) Distribution of fluorescence intensity of AF488-labeled cells. The scale $(\%)$ is the percent of cells with the indicated signal among $\mathrm{N}$ total cells; bin width is 20 . 

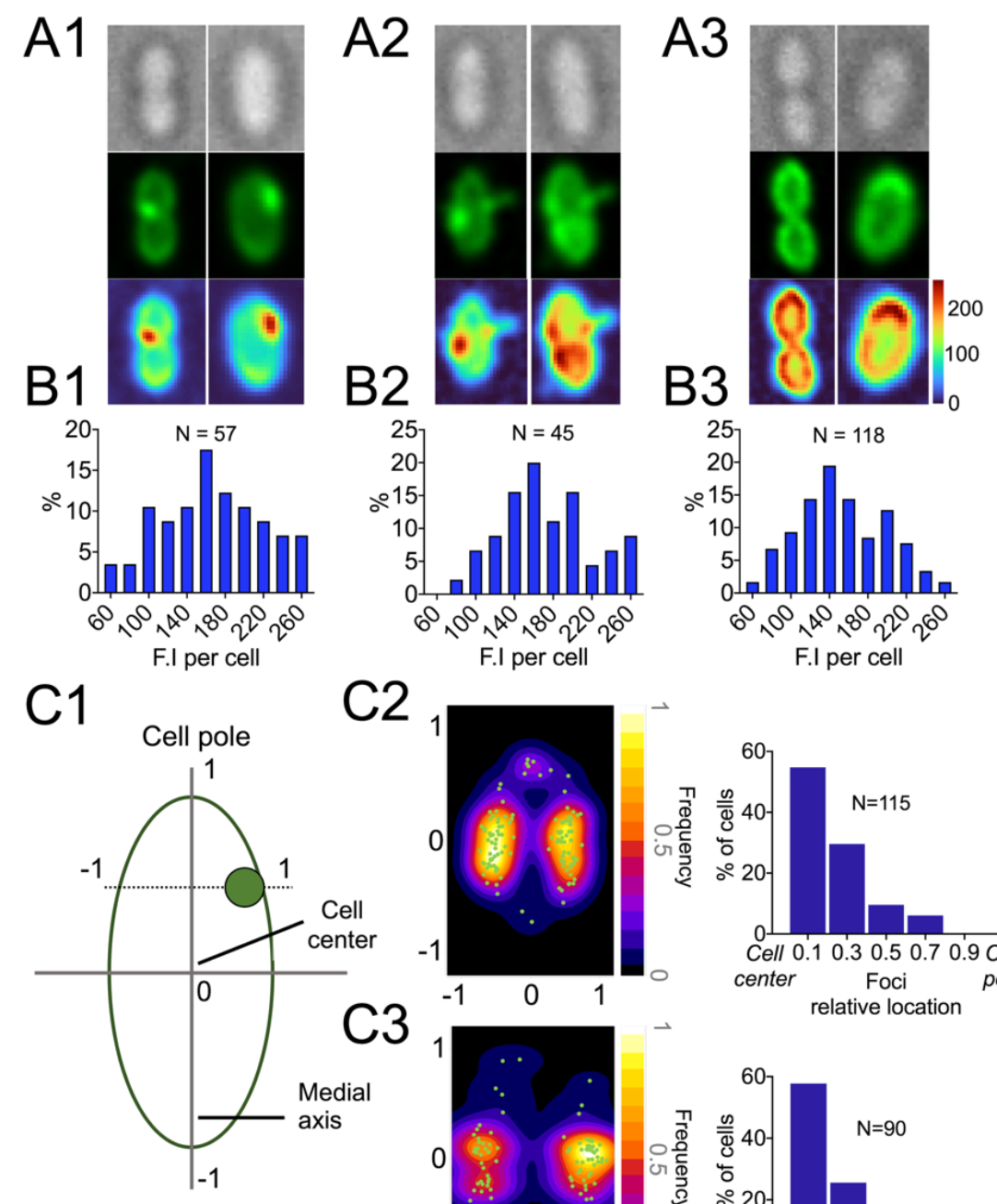

Cell pole

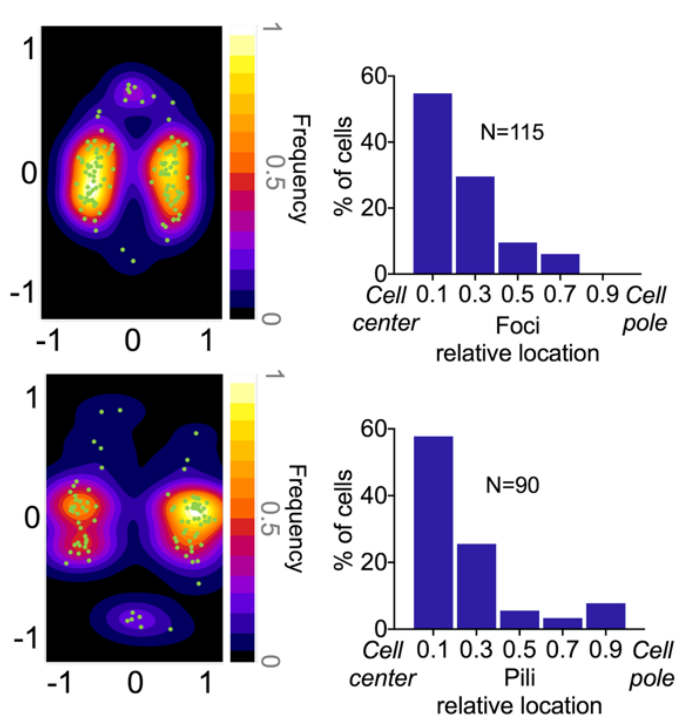

Figure 3. Localization of AF488-mal label in competent ComGC-Cys cells. Three classes of fluorescent image were distinguished: (A1) cells with a single bright focus; (A2) cells with a single extended appendage (with or without a focus); and (A3) cells with neither focus nor appendage. Top, DIC image; middle, deconvolved FITC image; bottom, cell fluorescence signal colormap (scale 0-255). Fluorescence intensity distribution of CSP-treated cells in each class: (B1) cells with a focus, (B2) cells with an extended appendage, or (B3) cells with neither. C1). Relative coordinates from cell center $(0)$ to poles $(-1$ or 1$)$, as used to represent focus or pilus location in $\mathrm{C} 2$ and C3. C2-C3) Localization of bright foci and extended appendages in N cells. Images that were used for the analysis are shown in Fig. \$4 and \$6. Left: heatmap of foci or extended appendages distribution; right: histogram of foci or extended appendage base location. Method of extended appendages detection is shown in Fig. S5. (Bin width: 0.2). 

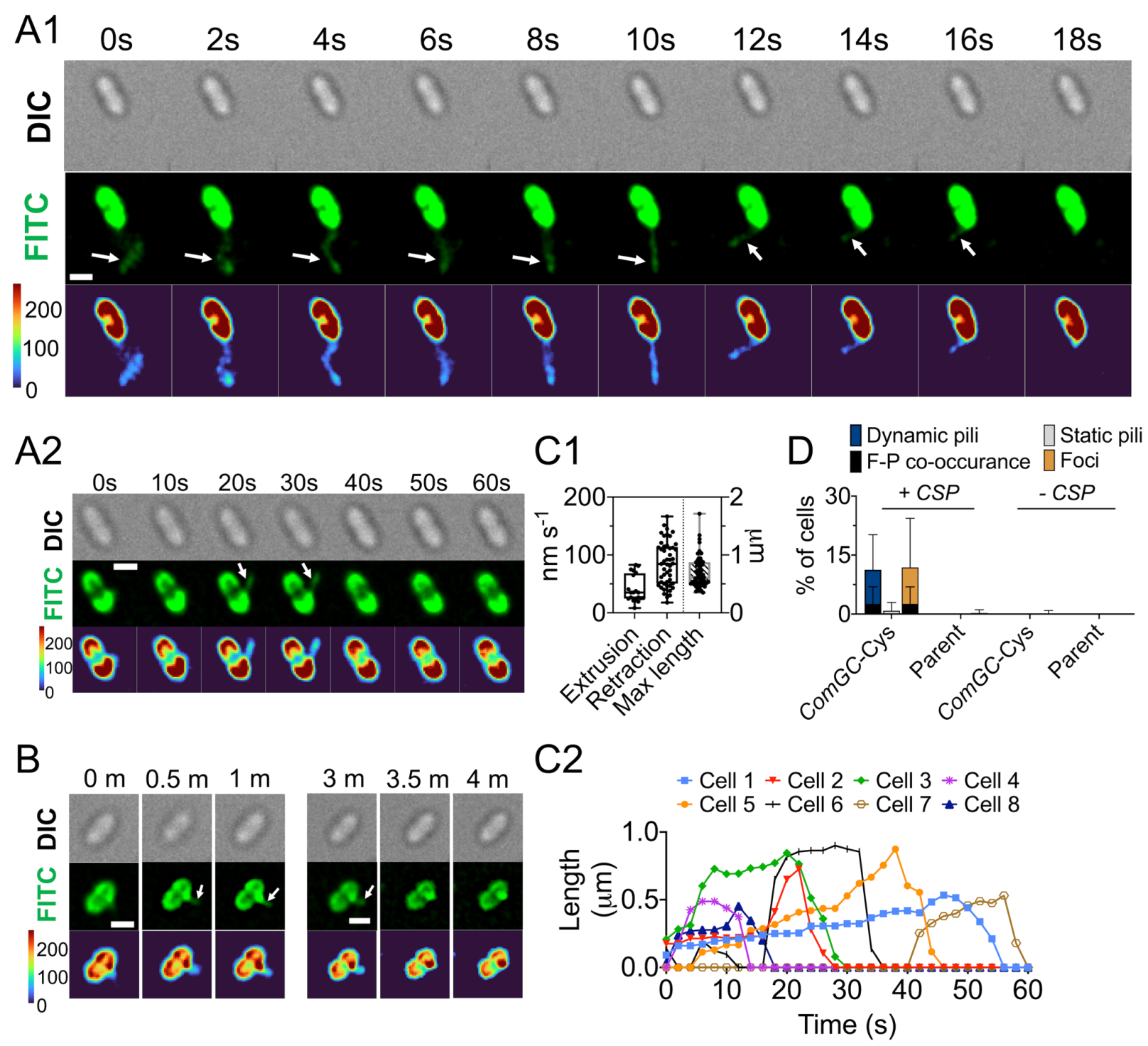

Figure 4. Dynamics of competence pilus activity. (A1 and A2) Deconvolved time-lapse imaging of ComGC-Cys cells with competence pilus labeled with AF488-mal. Panels: top, DIC; middle, FITC; bottom, colormap of cell fluorescence signal (scale 0-255). Arrows indicate pili. Scale bars, $1 \mu \mathrm{m}$. Time elapsed after capture of the first image is indicated. B) Persistence of ComGC-Cys pilus activity. Time-lapse images were taken for 1 minute with 2-sec intervals, followed by 2-minute break, and another 1-min 2-sec-interval time-lapse series of the same cell. Arrows indicate pilus. Scale bar, $1 \mu \mathrm{m}$. C1) Extrusion rate, retraction rate $\left(\mathrm{nm} \mathrm{s}^{-1}\right)$, and maximal length of a pilus analyzed in $\mathrm{N}$ cells (extrusion: $\mathrm{N}=20$; retraction: $\mathrm{N}=49$; max length: $\mathrm{N}=55$ ). $\mathrm{C2}$ ) Pilus dynamic kinetics of 8 representative cells. Cells that were used in the analysis are shown in Fig. S7-S14 and Movies S8-S15. D) Quantification of time-lapse images of competent (+CSP) and non-competent (-CSP) ComGC-Cys and parental cells labeled with AF488-mal ( $\mathrm{N}=2332$ and $\mathrm{N}=510$ for competent ComGC-Cys and parent cells, respectively; $\mathrm{N}=609$ and $\mathrm{N}=629$ for noncompetent ComGC-Cys and parent cells, respectively). The percent (\%) of cells indicates the fraction of cells with mobile pili, static pili, or foci among the total number of cells per frame within a 1-minute time period. 

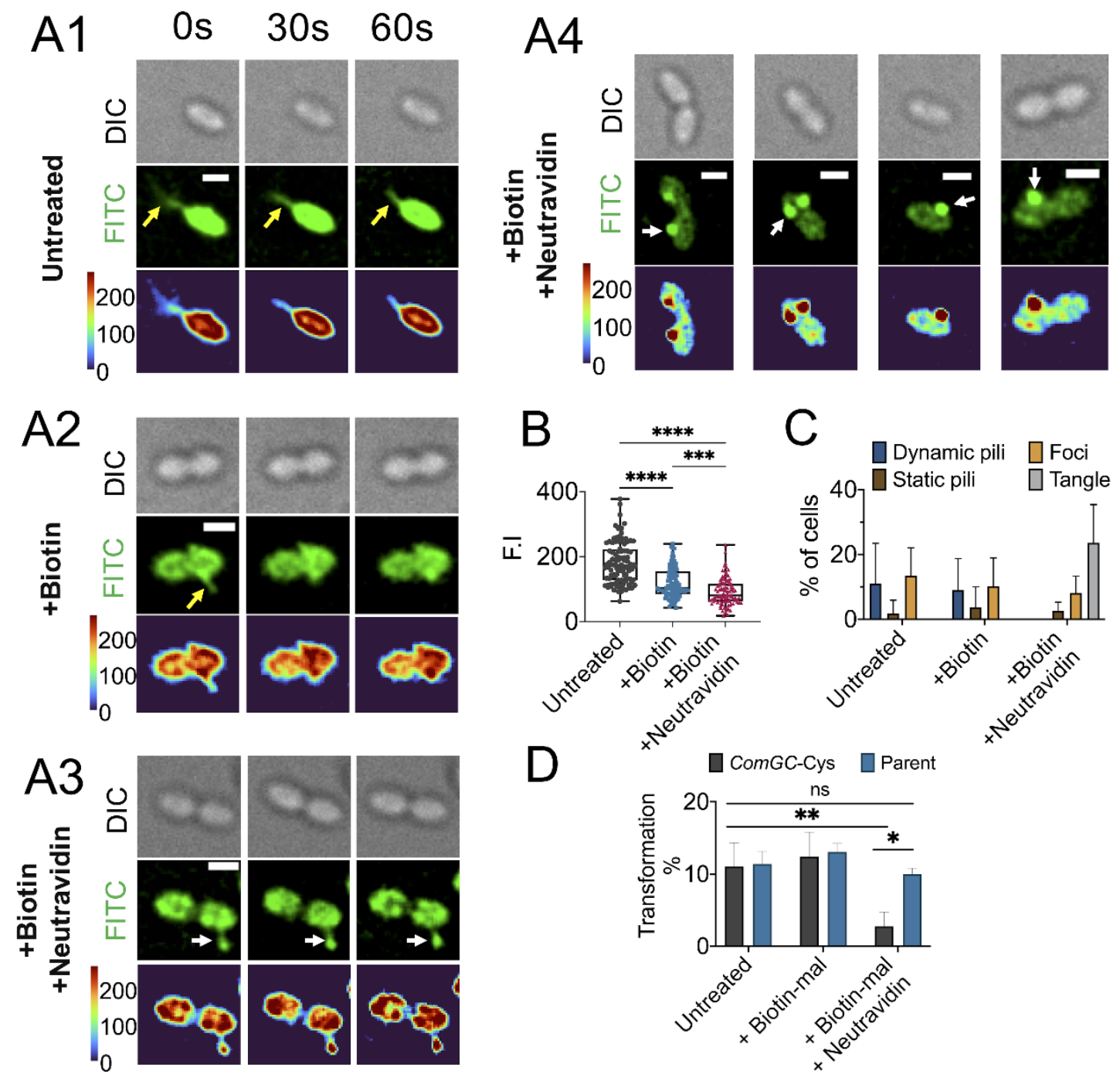

Figure 5. Pilus retraction is required for DNA uptake and transformation. A1-A3) Montage of time-lapse imaging of ComGC-Cys cells labeled with A1) AF488-mal, A2) biotin-mal plus AF488-mal, or A3) biotin-mal, AF488mal, and Neutravidin. A4) Representative static images of pilus tangle found in cells treated with biotin and Neutravidin. Top panels, DIC; middle panels, fluorescent images with FITC filter; bottom panels, colormap created for fluorescence signals. White arrows, static pili or tangle pili. Yellow arrows: mobile pili. Scale bar, $1 \mu \mathrm{m}$. B) Comparison of fluorescence signal among ComGC-Cys cells after the indicated treatments ( $\mathrm{N}=100$ for each condition, see supplemetal Fig. S15 and S16). C) Quantification of time-lapse images of ComGCCys competent cells labeled with AF488-mal (untreated, $\mathrm{N}=153$ ), biotin-mal plus AF488-mal (+biotin, $\mathrm{N}=143$ ), or biotin-mal, AF488mal, and Neutravidin (+biotin + neutravidin, $\mathrm{N}=242$ ). The percent $(\%)$ of cells indicates the fraction of cells with dynamic pili, static pili, foci, and tangle pili among the total number of cells per frame within a 1-minute time period. D) Effects of Neutravidin on transformation efficiency in ComGC-Cys and parent strains. Statistical analysis was done with one way ANOVA with Tukey's post-hoc analysis (ns: non-significant, ${ }^{* * *} \mathrm{P}<0.0001,{ }^{* *} \mathrm{P}<0.01$ ). 


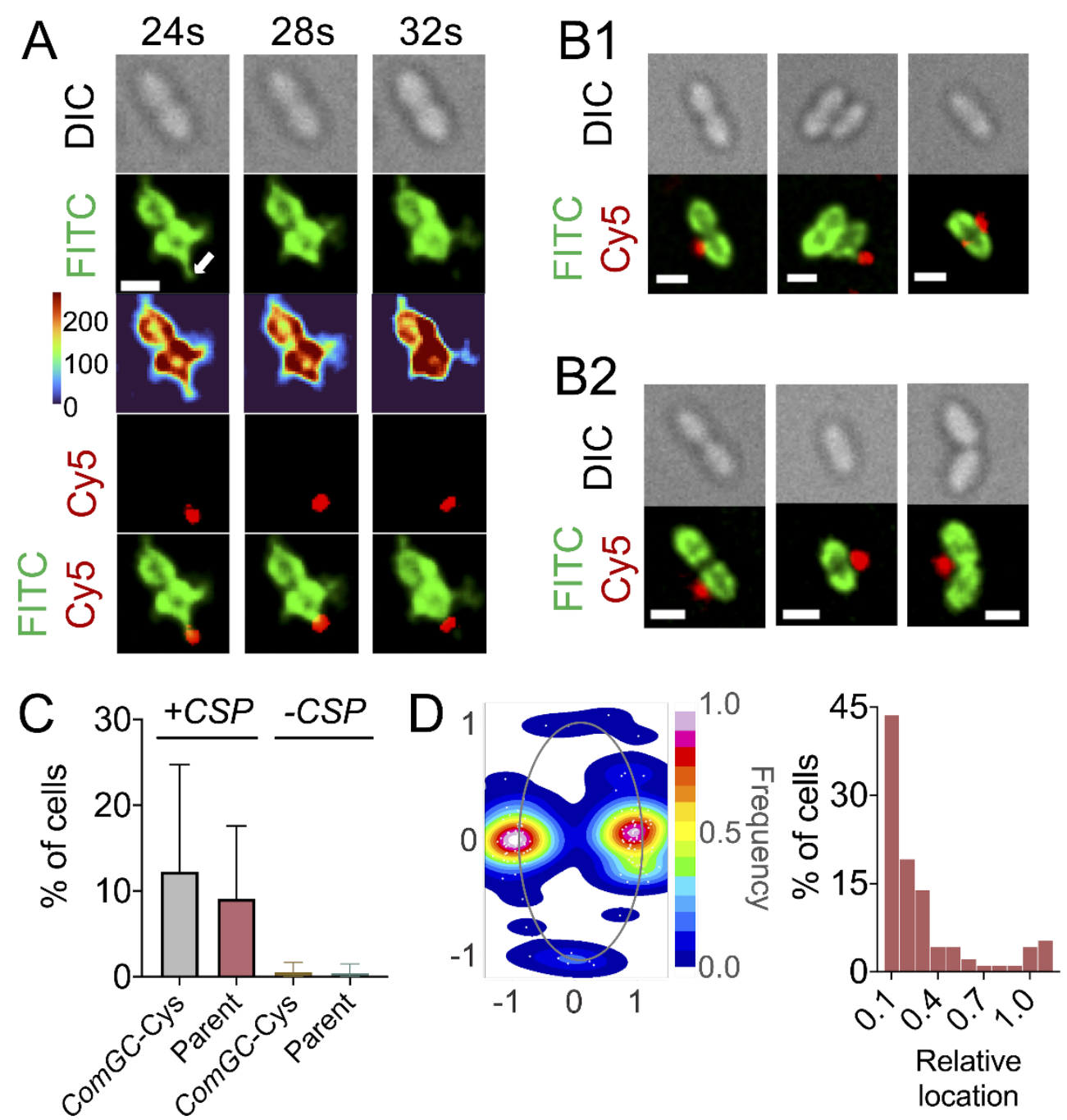

Figure 6. Interaction of competent ComGC-Cys or parent cells with Cy5-lambda DNA. A) Dynamic interaction of ComGC-Cys mutant with Lambda DNA (Movie S16-S17). From top to bottom: $1^{\text {st }}$ panel: DIC; $2^{\text {nd }}$ panel: fluorescent cells and pilus imaged using a FITC filter; 3rd panel: colormap created for cell and pilus fluorescence signals; 4th panel: Cy5-labeled DNA imaged using a Cy5 filter; 5th panel: merged images of Cy5 (DNA) and FITC (cells and pilus) channels. Full montage of time-lapse imaging is shown in Fig. S17. White arrow indicates pilus. Scale bar, $1 \mu \mathrm{m}$. B) DNA-bound competent cells of ComGC-Cys (B1) and parent strain (B2). Scale bars, $1 \mu \mathrm{m}$. C) Comparison of number of cells with bound DNA for competent $(+\mathrm{CSP})$ and non-competent (-CSP) ComGC-Cys and parent cells. DNA-bound cells were manually counted during 1-min timelapse imaging and qualified only if DNA remained close (distance from DNA fragment to cell body $<0.08 \mu \mathrm{m}$ ) to the cell body for at least 10 seconds during that time $(\mathrm{N}=2332$ and $\mathrm{N}=609$ for competent and non-competent Com $C$ C-Cys, respectively; $\mathrm{N}=510$ and $\mathrm{N}=629$ for competent and non-competent parent strain, respectively). D) DNA binding location mapping and distribution in 113 pneumococcal cells. 


\section{Bibliography}

1. Antonova, E. S. \& Hammer, B. K. 2015. Genetics of Natural Competence in Vibrio cholerae and other Vibrios. Microbiol Spectr, 3.

2. Bartlett, D. H. \& Azam, F. 2005. Chitin, Cholera, and Competence. Science, 310, 1775.

3. Bergé, M. J., Kamgoué, A., Martin, B., Polard, P., Campo, N. \& Claverys, J.-P. 2013. Midcell Recruitment of the DNA Uptake and Virulence Nuclease, EndA, for Pneumococcal Transformation. PLOS Pathogens, 9, e1003596.

4. Berry, J. L. \& Pelicic, V. 2015. Exceptionally widespread nanomachines composed of type IV pilins: the prokaryotic Swiss Army knives. FEMS Microbiol Rev, 39, 134-54.

5. Bonazzi, D., Lo Schiavo, V., Machata, S., Djafer-Cherif, I., Nivoit, P., Manriquez, V., ... Duménil, G. 2018. Intermittent Pili-Mediated Forces Fluidize Neisseria meningitidis Aggregates Promoting Vascular Colonization. Cell, 174, 143-155.e16.

6. Boonstra, M., Vesel, N. \& Kuipers, O. P. 2018. Fluorescently Labeled DNA Interacts with Competence and Recombination Proteins and Is Integrated and Expressed Following Natural Transformation of Bacillus subtilis. mBio, 9, e01161-18.

7. Bradley, D. E. 1980. A function of Pseudomonas aeruginosa PAO polar pili: twitching motility. Canadian Journal of Microbiology, 26, 146-154.

8. Burrows, L. 2005. Weapons of mass retraction. Molecular microbiology, 57, 878-88.

9. Burton, B. \& Dubnau, D. 2010. Membrane-associated DNA Transport Machines. Cold Spring Harbor Perspectives in Biology, 2.

10. Carbonnelle, E., Helaine, S., Nassif, X. \& Pelicic, V. 2006. A systematic genetic analysis in Neisseria meningitidis defines the Pil proteins required for assembly, functionality, stabilization and export of type IV pili. Molecular Microbiology, 61, 1510-1522.

11. Cehovin, A., Simpson, P. J., Mcdowell, M. A., Brown, D. R., Noschese, R., Pallett, M., ... Pelicic, V. 2013. Specific DNA recognition mediated by a type IV pilin. Proceedings of the National Academy of Sciences, 110, 3065.

12. Cha, R. S., Zarbl, H., Keohavong, P. \& Thilly, W. G. 1992. Mismatch amplification mutation assay (MAMA): application to the c-H-ras gene. PCR Methods Appl, 2, 14-20.

13. Chamot-Rooke, J., Mikaty, G., Malosse, C., Soyer, M., Dumont, A., Gault, J., ... Duménil, G. 2011. Posttranslational modification of pili upon cell contact triggers N. meningitidis dissemination. Science, 331, 778-82.

14. Chang, J. C., Lasarre, B., Jimenez, J. C., Aggarwal, C. \& Federle, M. J. 2011. Two Group A Streptococcal Peptide Pheromones Act through Opposing Rgg Regulators to Control Biofilm Development. PLOS Pathogens, 7, e1002190.

15. Chen, I. \& Dubnau, D. 2004. DNA uptake during bacterial transformation. Nature Reviews Microbiology, 2, 241-249.

16. Chen, I., Christie, P. J. \& Dubnau, D. 2005. The ins and outs of DNA transfer in bacteria. Science, 310, 1456-60.

17. Chen, I., Provvedi, R. \& Dubnau, D. 2006. A macromolecular complex formed by a pilinlike protein in competent Bacillus subtilis. The Journal of biological chemistry, 281, 21720 21727.

18. Chlebek, J. L., Hughes, H. Q., Ratkiewicz, A. S., Rayyan, R., Wang, J. C.-Y., Herrin, B. E., ... Dalia, A. B. 2019. PilT and PilU are homohexameric ATPases that coordinate to retract type IVa pili. PLOS Genetics, 15, e1008448.

19. Cowley, L. A., Petersen, F. C., Junges, R., Jimson D. Jimenez, M., Morrison, D. A. \& Hanage, W. P. 2018. Evolution via recombination: Cell-to-cell contact facilitates larger recombination events in Streptococcus pneumoniae. PLOS Genetics, 14, e1007410. 
20. Craig, L., Volkmann, N., Arvai, A. S., Pique, M. E., Yeager, M., Egelman, E. H. \& Tainer, J. A. 2006. Type IV pilus structure by cryo-electron microscopy and crystallography: implications for pilus assembly and functions. Mol Cell, 23, 651-62.

21. Denise, R., Abby, S. S. \& Rocha, E. P. C. 2019. Diversification of the type IV filament superfamily into machines for adhesion, protein secretion, DNA uptake, and motility. PLOS Biology, 17, e3000390.

22. Diallo, A., Foster, H. R., Gromek, K. A., Perry, T. N., Dujeancourt, A., Krasteva, P. V., ... Fronzes, R. 2017. Bacterial transformation: ComFA is a DNA-dependent ATPase that forms complexes with ComFC and DprA. Mol Microbiol, 105, 741-754.

23. Dubnau, D. \& Blokesch, M. 2019. Mechanisms of DNA Uptake by Naturally Competent Bacteria. Annual Review of Genetics, 53, 1-21.

24. Ellison, C. K., Kan, J., Dillard, R. S., Kysela, D. T., Ducret, A., Berne, C., ... Brun, Y. V. 2017. Obstruction of pilus retraction stimulates bacterial surface sensing. Science, 358, 535-538.

25. Ellison, C. K., Dalia, T. N., Vidal Ceballos, A., Wang, J. C.-Y., Biais, N., Brun, Y. V. \& Dalia, A. B. 2018. Retraction of DNA-bound type IV competence pili initiates DNA uptake during natural transformation in Vibrio cholerae. Nature Microbiology, 3, 773-780.

26. Ellison, C. K., Dalia, T. N., Dalia, A. B. \& Brun, Y. V. 2019. Real-time microscopy and physical perturbation of bacterial pili using maleimide-conjugated molecules. Nature Protocols, 14, 1803-1819.

27. Ellison, C. K., Kan, J., Chlebek, J. L., Hummels, K. R., Panis, G., Viollier, P. H., ... Brun, Y. V. 2019. A bifunctional ATPase drives tad pilus extension and retraction. Science Advances, 5, eaay2591.

28. Farinha, M. A., Conway, B. D., Glasier, L. M., Ellert, N. W., Irvin, R. T., Sherburne, R. \& Paranchych, W. 1994. Alteration of the pilin adhesin of Pseudomonas aeruginosa PAO results in normal pilus biogenesis but a loss of adherence to human pneumocyte cells and decreased virulence in mice. Infection and immunity, 62, 4118-4123.

29. Harding, C. M., Tracy, E. N., Carruthers, M. D., Rather, P. N., Actis, L. A. \& Munson, R. S., Jr. 2013. Acinetobacter baumannii strain M2 produces type IV pili which play a role in natural transformation and twitching motility but not surface-associated motility. mBio, 4.

30. Håvarstein, L. S., Coomaraswamy, G. \& Morrison, D. A. 1995. An unmodified heptadecapeptide pheromone induces competence for genetic transformation in Streptococcus pneumoniae. Proceedings of the National Academy of Sciences of the United States of America, 92, 11140-11144.

31. Hepp, C. \& Maier, B. 2016. Kinetics of DNA uptake during transformation provide evidence for a translocation ratchet mechanism. Proceedings of the National Academy of Sciences of the United States of America, 113, 12467-12472.

32. Herzberg, C., Friedrich, A. \& Averhoff, B. 2000. comB, a novel competence gene required for natural transformation of Acinetobacter sp. BD413: identification, characterization, and analysis of growth-phase-dependent regulation. Arch Microbiol, 173, 220-8.

33. Higashi, D. L., Lee, S. W., Snyder, A., Weyand, N. J., Bakke, A. \& So, M. 2007. Dynamics of Neisseria gonorrhoeae Attachment: Microcolony Development, Cortical Plaque Formation, and Cytoprotection. Infection and Immunity, 75, 4743.

34. Hockenberry, A. M., Hutchens, D. M., Agellon, A. \& So, M. 2016. Attenuation of the Type IV Pilus Retraction Motor Influences Neisseria gonorrhoeae Social and Infection Behavior. mBio, 7.

35. Imam, S., Chen, Z., Roos, D. S. \& Pohlschröder, M. 2011. Identification of surprisingly diverse type IV pili, across a broad range of gram-positive bacteria. PLoS One, 6, e28919.

36. Johnsborg, O., Eldholm, V., Bjørnstad, M. L. \& Håvarstein, L. S. 2008. A predatory mechanism dramatically increases the efficiency of lateral gene transfer in Streptococcus pneumoniae and related commensal species. Molecular Microbiology, 69, 245-253. 
37. Jurcisek, J. A. \& Bakaletz, L. O. 2007. Biofilms formed by nontypeable Haemophilus influenzae in vivo contain both double-stranded DNA and type IV pilin protein. J Bacteriol, 189, 3868-75.

38. Kelley, L. A., Mezulis, S., Yates, C. M., Wass, M. N. \& Sternberg, M. J. E. 2015. The Phyre2 web portal for protein modeling, prediction and analysis. Nature Protocols, 10, 845-858.

39. Khan, R., Rukke, H. V., Høvik, H., Åmdal, H. A., Chen, T., Morrison, D. A. \& Petersen, F. C. 2016. Comprehensive Transcriptome Profiles of Streptococcus mutans UA159 Map Core Streptococcal Competence Genes. mSystems, 1, e00038-15.

40. Klausen, M., Heydorn, A., Ragas, P., Lambertsen, L., Aaes-Jørgensen, A., Molin, S. \& Tolker-Nielsen, T. 2003. Biofilm formation by Pseudomonas aeruginosa wild type, flagella and type IV pili mutants. Molecular Microbiology, 48, 1511-1524.

41. Koomey, M. 1998. Competence for natural transformation in Neisseria gonorrhoeae: a model system for studies of horizontal gene transfer. APMIS Suppl, 84, 56-61.

42. Lam, T., Brennan, M. D., Morrison, D. A. \& Eddington, D. T. 2019. Femtoliter droplet confinement of Streptococcus pneumoniae: bacterial genetic transformation by cell-cell interaction in droplets. Lab on a Chip, 19, 682-692.

43. Lam, T., Maienschein-Cline, M., Eddington, D. T. \& Morrison, D. A. 2019. Multiplex gene transfer by genetic transformation between isolated $S$. pneumoniae cells confined in microfluidic droplets. Integrative Biology, 11, 415-424.

44. Laurenceau, R., Péhau-Arnaudet, G., Baconnais, S., Gault, J., Malosse, C., Dujeancourt, A., ... Fronzes, R. 2013. A Type IV Pilus Mediates DNA Binding during Natural Transformation in Streptococcus pneumoniae. PLOS Pathogens, 9, e1003473.

45. Liu, Y., Zeng, Y., Huang, Y., Gu, L., Wang, S., Li, C., ... Zhang, J.-R. 2019. HtrA-mediated selective degradation of DNA uptake apparatus accelerates termination of pneumococcal transformation. Molecular Microbiology, 112, 1308-1325.

46. Maier, B., Potter, L., So, M., Seifert, H. S. \& Sheetz, M. P. 2002. Single pilus motor forces exceed 100 pN. Proceedings of the National Academy of Sciences, 99, 16012.

47. Marttila, A. T., Laitinen, O. H., Airenne, K. J., Kulik, T., Bayer, E. A., Wilchek, M. \& Kulomaa, M. S. 2000. Recombinant NeutraLite avidin: a non-glycosylated, acidic mutant of chicken avidin that exhibits high affinity for biotin and low non-specific binding properties. FEBS Lett, 467, 31-6.

48. Mattick, J. S. 2002. Type IV pili and twitching motility. Annu Rev Microbiol, 56, 289-314.

49. Mell, J. C., Hall, I. M. \& Redfield, R. J. 2012. Defining the DNA uptake specificity of naturally competent Haemophilus influenzae cells. Nucleic acids research, 40, 8536-8549.

50. Melville, S. \& Craig, L. 2013. Type IV pili in Gram-positive bacteria. Microbiology and molecular biology reviews : MMBR, 77, 323-341.

51. Merz, A. J., So, M. \& Sheetz, M. P. 2000. Pilus retraction powers bacterial twitching motility. Nature, 407, 98-102.

52. Mirouze, N., Bergé, M. A., Soulet, A. L., Mortier-Barrière, I., Quentin, Y., Fichant, G., ... Claverys, J. P. 2013. Direct involvement of DprA, the transformation-dedicated RecA loader, in the shut-off of pneumococcal competence. Proc Natl Acad Sci U S A, 110, E1035-44.

53. Morrison, D. A. 1979. [21] Transformation and preservation of competent bacterial cells by freezing. Methods in Enzymology. Academic Press.

54. Muschiol, S., Erlendsson, S., Aschtgen, M.-S., Oliveira, V., Schmieder, P., De Lichtenberg, C., ... Henriques-Normark, B. 2017. Structure of the competence pilus major pilin ComGC in Streptococcus pneumoniae. The Journal of biological chemistry, 292, 14134-14146.

55. Muschiol, S., Aschtgen, M. S., Nannapaneni, P. \& Henriques-Normark, B. 2019. GramPositive Type IV Pili and Competence. Microbiol Spectr, 7. 
56. Nieto, V., Kroken, A. R., Grosser, M. R., Smith, B. E., Metruccio, M. M. E., Hagan, P., ... Fleiszig, S. M. J. 2019. Type IV Pili Can Mediate Bacterial Motility within Epithelial Cells. mBio, 10, e02880-18.

57. Oliveira, V. 2020. Competence Pilus Biogenesis In Streptococcus Pneumoniae. Ph.D, Karolinska Institutet, Stockholm, Sweden.

58. Parge, H. E., Forest, K. T., Hickey, M. J., Christensen, D. A., Getzoff, E. D. \& Tainer, J. A. 1995. Structure of the fibre-forming protein pilin at $2.6 \AA$ resolution. Nature, 378, 32-38.

59. Parker, D., Kennan, R. M., Myers, G. S., Paulsen, I. T., Songer, J. G. \& Rood, J. I. 2006. Regulation of Type IV Fimbrial Biogenesis in Dichelobacter nodosus. Journal of Bacteriology, 188, 4801.

60. Petersen, B., Petersen, T. N., Andersen, P., Nielsen, M. \& Lundegaard, C. 2009. A generic method for assignment of reliability scores applied to solvent accessibility predictions. BMC Structural Biology, 9, 51.

61. Peterson, S. N., Sung, C. K., Cline, R., Desai, B. V., Snesrud, E. C., Luo, P., ... Morrison, D. A. 2004. Identification of competence pheromone responsive genes in Streptococcus pneumoniae by use of DNA microarrays. Mol Microbiol, 51, 1051-70.

62. Pettersen, E. F., Goddard, T. D., Huang, C. C., Couch, G. S., Greenblatt, D. M., Meng, E. C. \& Ferrin, T. E. 2004. UCSF Chimera--a visualization system for exploratory research and analysis. J Comput Chem, 25, 1605-12.

63. Piepenbrink, K. H. \& Sundberg, E. J. 2016. Motility and adhesion through type IV pili in Gram-positive bacteria. Biochemical Society Transactions, 44, 1659-1666.

64. Piepenbrink, K. H. 2019. DNA Uptake by Type IV Filaments. Frontiers in Molecular Biosciences, 6.

65. Pönisch, W., Weber, C., Juckeland, G., Biais, N. \& Zaburdaev, V. 2017. Multiscale Modeling of Bacterial Colonies: How Pili Mediate the Dynamics of Single Cells and Cellular Aggregates. New Journal of Physics, 19, 015003.

66. Porstendörfer, D., Gohl, O., Mayer, F. \& Averhoff, B. 2000. ComP, a pilin-like protein essential for natural competence in Acinetobacter sp. Strain BD413: regulation, modification, and cellular localization. J Bacteriol, 182, 3673-80.

67. Pozzi, G., Masala, L., lannelli, F., Manganelli, R., Havarstein, L. S., Piccoli, L., ... Morrison, D. A. 1996. Competence for genetic transformation in encapsulated strains of Streptococcus pneumoniae: two allelic variants of the peptide pheromone. Journal of bacteriology, 178, 6087-6090.

68. Sabass, B., Koch, M. D., Liu, G., Stone, H. A. \& Shaevitz, J. W. 2017. Force generation by groups of migrating bacteria. Proc Natl Acad Sci U S A, 114, 7266-7271.

69. Seitz, P. \& Blokesch, M. 2013. DNA-uptake machinery of naturally competent Vibrio cholerae. Proceedings of the National Academy of Sciences, 110, 17987-17992.

70. Shoemaker, N. B. \& Guild, W. R. 1972. Kinetics of integration of transforming DNA in pneumococcus. Proceedings of the National Academy of Sciences of the United States of America, 69, 3331-3335.

71. Skerker, J. M. \& Berg, H. C. 2001. Direct observation of extension and retraction of type IV pili. Proceedings of the National Academy of Sciences, 98, 6901.

72. Stone, B. J. \& Kwaik, Y. A. 1999. Natural competence for DNA transformation by Legionella pneumophila and its association with expression of type IV pili. Journal of bacteriology, 181, 1395-1402.

73. Tovpeko, Y. \& Morrison, D. A. 2014. Competence for genetic transformation in Streptococcus pneumoniae: mutations in $\sigma A$ bypass the comW requirement. Journal of bacteriology, 196, 3724-3734.

74. Welker, A., Cronenberg, T., Zöllner, R., Meel, C., Siewering, K., Bender, N., ... Maier, B. 2018. Molecular Motors Govern Liquidlike Ordering and Fusion Dynamics of Bacterial Colonies. Physical review letters, 121, 118102. 
75. Weng, L., Piotrowski, A. \& Morrison, D. A. 2013. Exit from Competence for Genetic Transformation in Streptococcus pneumoniae Is Regulated at Multiple Levels. PLOS ONE, 8, e64197.

76. Whitchurch, C. B., Hobbs, M., Livingston, S. P., Krishnapillai, V. \& Mattick, J. S. 1991. Characterisation of a Pseudomonas aeruginosa twitching motility gene and evidence for a specialised protein export system widespread in eubacteria. Gene, 101, 33-44. 